\title{
Z. Harris: a imperfeição e o acesso à língua
}

\author{
Núbia Rabelo Bakker Faria ${ }^{1}$
}

\section{Resumo}

Este artigo, de natureza teórica, reflete sobre os problemas que a segmentação das cadeias da fala em unidades linguísticas levanta para uma abordagem inatista on não-inatista de aquisição de linguagem, confrontando dois autores: Z. Harris e N. Chomsky. Para tratar das formas de acesso à língua através da fala, Z. Harris em Structural linguistics volta-se para a definição, distribuição e ocorrência das unidades linguísticas, assim como para a demarcação de limites entre elas. O testemunho da falha na realização da unidade terá no método função residual, porém significativa para a comprovação da correta segmentação: a falba mostra-se regida por restrições que operam na lingua. Opondo-se a Harris, a imperfeição do input foi tomada por Chomsky como argumento lógico para a hipótese inatista, inaugurando a Gramática Gerativa e demarcando um espaço de teorização para a área da aquisição de linguagem. O que veio a ser qualificado de imperfeito por Chomsky mostra-se, na linguística de Harris, via de acesso à língua de outrem.

Palavras-chave: Fala. Segmentação. Unidades linguisticas. Imperfeição. Input

\footnotetext{
${ }^{1}$ Possui graduação em Pedagogia pela Universidade de Brasília (1983), mestrado e doutorado em Letras e Linguística pela Universidade Federal de Alagoas (1997; 2001). Atualmente é professora ativa permanente, Associado 4, da Universidade Federal de Alagoas. Tem experiência na área de Linguística, com ênfase em Aquisição de Linguagem, Teoria Linguística, atuando principalmente nos seguintes temas: aquisição de linguagem oral e escrita, teorias linguísticas e estudos saussurianos. É membro do GT Estudos Saussurianos da Anpoll.
} 


\section{Z. Harris: a imperfeição e o acesso à lingua}

Núbia Rabelo Bakker Faria

\section{Introdução}

Este trabalho parte da constatação de que, na reflexão linguística, as menções feitas à criança e à aquisição da sua língua materna não se limitam à Gramática Gerativa, que tornará a questão particularmente central na construção de seu modelo teórico. Em a Vida da linguagem, W. D. Whitney (2010 [1875]) consagra um capítulo a discutir "Como cada homem adquire sua língua: a vida da linguagem”, atrelando claramente o título de seu livro à questão da aquisição da linguagem. Saussure afirma no Curso de Linguística Geral (CLG) de 1916: "Será mister lembrar também a soma de esforços que exige o aprendizado da língua materna" (SAUSSURE, 2006, p. 86). Encontramos nas páginas de abertura da obra clássica de Sapir A linguagem: introdução ao estudo da fala, de 1921: "O processo de aquisição da linguagem é, em suma, coisa completamente diversa do processo de aprender a andar" (SAPIR, 1971, p. 17). É notória a passagem em que Bloomfield refere-se aos pequenos Jack e Jill em Language, de 1933, aplicando as premissas do behaviorismo de Watson para ilustrar sua versão sobre o aparecimento da linguagem.

Minimamente, a menção à criança convoca o problema de seu acesso à língua da comunidade da qual faz parte, ou melhor, à materialidade linguística que se apresenta necessariamente na fala, ponto importante, se considerarmos que será com a fala que a área da aquisição de linguagem precisará lidar: seja a fala da criança, tomada como dado empírico, seja a fala da comunidade, entendida como input linguístico. A segmentação das cadeias sonoras em unidades levanta problemas nada triviais, tanto numa abordagem inatista, quanto numa não inatista da aquisição de linguagem, e nos remete, forçosamente, a um dos pontos centrais do empreendimento estruturalista no campo da Linguística.

Em Saussure and his interpreters, Roy Harris dedica um capítulo a Bloomfield e o inicia assim: "Leonard Bloomfield, eventually to become the most influential figure in American linguistics in the first half of the twentieth century, agreed that the CLG had 'given us the theoretical basis for a Science of human speech"”2 (HARRIS, R., 2003, p. 59).

Estabelecer sua vinculação ao projeto teórico de Saussure apelando para a fala (speech) e não para a língua, como faz Bloomfield, exige reflexão. Encontramos em Ducrot (1970), ao discutir o estruturalismo em linguística, a afirmação por ele próprio destacada:

\footnotetext{
${ }^{2}$ Leonard Bloomfield, que veio a se tornar a figura mais influente na linguística americana na primeira metade do século vinte, reconheceu que o CLG "nos forneceu as bases para a Ciência da fala humana" (Todas as traduções em notas de rodapé dos textos citados em inglês no corpo deste trabalho foram feitas por nós).
} 
"Pressupor no elemento o sistema, eis o que constitui, a nosso ver, o contributo próprio de Saussure ao Estruturalismo linguístico” (p. 56). Na sequência dessa discussão, prossegue o autor:

Para o reconhecimento dos elementos cujo jogo compõe a fala, duas tarefas devem ser levadas a cabo, tarefas que assumiram, desde Saussure, uma importância preponderante na atividade dos linguistas. A primeira é segmentar o discurso em componentes, sucessivos ou simultâneos. [A segunda tarefa é] poder reencontrar o mesmo componente em ocorrências e amiúde em contextos diferentes, onde ele pode aparecer sob formas assaz distintas (DUCROT, 1970, p. 57 - grifo nosso).

A inexistência de fronteiras naturais entre as unidades da língua presentes na cadeia da fala coloca, para o estruturalismo que surge em torno do nome de Saussure, um problema teórico-metodológico para abordar um fenômeno, cujo modo de existência desafia a ciência da época: "A língua apresenta, pois este caráter estranho e surpreendente de não oferecer entidades perceptíveis à primeira vista, sem que se possa duvidar, entretanto, de que existam e que é seu jogo que a constitui” (SAUSSURE, 2006, p. 124).

As relações entre os esforços da linguística americana para construir para si um método e o desafio lançado por Saussure são bastante complexas, como pode ser observado na análise feita por R. Harris acima referida. Não nos deteremos em tal discussão. Interessa-nos ressaltar os efeitos, para a reflexão linguística, advindos do reconhecimento saussuriano de que "o essencial da língua [...] é estranho ao caráter fônico do signo" (SAUSSURE, 2006, p.14), com todas as consequências daí decorrentes. Esses efeitos parecem-nos exemplares no caso da linguística estruturalista americana, que se dedicou à descrição de línguas indígenas do continente, sem poder apoiar-se na semelhança entre as línguas, como ocorreu com a linguística europeia, notadamente no período histórico-comparatista.

O encontro com o inusitado das chamadas "línguas exóticas" americanas, reportanos ao que diz Saussure ao tratar do método de delimitação das unidades linguísticas:

Quando ouvimos uma língua desconhecida, somos incapazes de dizer como a sequência de sons deve ser analisada; é que essa análise se torna impossível se se levar em conta somente o aspecto fônico do fenômeno linguístico. Mas quando sabemos que significado e que papel atribuir a cada parte da sequência, vemos então tais partes se desprenderem uma das outras, e a fita amorfa partir-se em fragmentos. Essa análise não tem nada de material (SAUSSURE, 2006, p. 120). 
Embora não se trate de uma "análise material" em sentido estrito, a linguística americana não poderá prescindir da materialidade posta em jogo na fala, uma vez que o apelo à significação para a segmentação das unidades, referido por Saussure no exemplo das cadeias homófonas de sua língua materna (si je l'apprends e si je la prends) não ocorre.

Para conduzir a discussão a que nos propomos, privilegiamos neste trabalho a reflexão de Zellig Harris sobre a lingua e as possibilidades de acesso a ela através da fala. A escolha desse autor foi feita por entendermos haver entre sua reflexão e a de Chomsky, seu antigo orientando, desdobramentos interessantes para pensarmos nos impasses que o problema da segmentação das unidades linguísticas acarretará, quando está em questão a trajetória do infans, aquele que ainda não fala, a sujeito falante da língua da comunidade na qual foi inserido.

\section{Z. Harris e os resíduos do método}

Não há no trabalho de Z. Harris menção explícita à criança. Esta será suposta no item consagrado à definição de termos, nesse caso, falante nativo: "in general, any person past his first few years of learning to talk speaks the language of his community as 'a native"' (HARRIS, 1960, p. 13-14) ${ }^{3}$. Não obstante essa rápida referência, a sua vinculação ao empirismo psicológico dominante na escola bloomfieldiana convocará a "criança behaviorista" (aquela que aprende a falar) de tal maneira que, na virada dada por Chomsky à linguística americana, precisamente a partir de Z. Harris, será essa criança alvo das críticas mais contundentes (CHOMSKY, 1959). Em seu lugar se instalará absoluta a "criança racionalista".

Em Structural linguistics, de 1960, a quarta reedição de seu famoso livro de 1951, então nomeado Methods in structural linguistics, tem-se, conforme reconhecimento explícito da área, a tentativa mais ambiciosa e rigorosa da linguística americana na delimitação objetiva dos procedimentos a serem seguidos pelo linguista no tratamento dos dados da fala. Baseado no ideal de cientificidade e objetividade exigidos pela ciência positivista, Z. Harris, sem fazer apelo à significação, tenta explicitar, em procedimentos altamente precisos, os

\footnotetext{
3 "em geral, qualquer pessoa passados seus primeiros anos de aprendizagem da fala, fala a língua de sua comunidade como um nativo".
} 
passos necessários para a delimitação das unidades de uma língua. A análise da língua é entendida como derivada da análise da fala, aplicando-se sobre esta uma série de procedimentos que visam à demarcação de enunciados completos (whole utterances) e, a partir desses, a extração das unidades elementares: fonemas ou morfemas. O método linguístico traduz-se por "procedimentos de descoberta", como dirá Chomsky, negando o seu alcance.

Investigations in descriptive linguistic are usually conducted with reference to any number of whole utterances. Many of the results apply explicitly to whole utterances. Even when studies of particular interrelations among phonemes or morphemes classes are carried out, the frame within which these interrelations occur is usually referred ultimately to their position within an utterance (HARRIS, 1960, p. 11)5.

Ainda no item destinado à definição de termos, que antecede a apresentação do método propriamente dito, Harris afirma que:

An utterance is any stretch of talk, by one person, before and after which there is silence on the part of the person. The utterance is, in general, not identical with the 'sentence' (as the word is commonly used), since a great many utterances, in English, for example, consist of single words, phrases, 'incomplete sentences', etc. (HARRIS, 1960, p. 14)'.

Pelo acima exposto, fica definido que, no intervalo da fala compreendido entre dois momentos de silêncio, a tarefa do linguista será a de descobrir regularidades enfrentando todas as instâncias de uma fala não "editada". É importante registrar que, como afirma em nota de rodapé ao se referir em seu texto ao buman behavior, não é possível falar em "identifiable linguistic behavior, much less phonologic or morphologic behavior"” (HARRIS, 1960 , p. 22 - grifo nosso). Na mesma direção, afirma mais adiante o autor: "A phonemically written form therefore is not a direct record of some spoken form, but rather a record of its difference from all other spoken forms of the language” (HARRIS, 1960, p. 35

\footnotetext{
4 Conforme Borges Neto, (1991, p. 52), "Um procedimento de descoberta é uma técnica, um processo mecânico, que, aplicado ao corpus, garante a derivação das regras gramaticais que descrevem a estrutura dos enunciados constantes no corpus. Trata-se da formalização da 'lógica da descoberta' das gramáticas”.

5 "Investigações em linguística descritiva são geralmente conduzidas com referência a qualquer número de elocuções completas. Muitos resultados aplicam-se explicitamente a elocuções completas. Mesmo quando estudos de interrelações particulares entre classes de fonemas ou morfemas são conduzidos, o quadro dentro do qual se produzem essas interrelações geralmente se refere em última instância à sua posição dentro de uma elocução".

6 "Uma elocução é qualquer duração de fala, de uma pessoa, antes e depois da qual a pessoa silencia. A elocução, em geral, não é idêntica a uma 'sentença' (como a palavra é comumente usada), uma vez que inúmeras elocuções, em inglês, por exemplo, consistem em palavras isoladas, frase, sentenças incompletas".

7 “Comportamento linguístico identificável, muito menos comportamento fonológico ou morfológico".
} 
- grifo nosso) $)^{8}$. Ou seja, a escrita fonêmica não corresponde diretamente ao registro do som, unidade material sensível, mas à diferença entre essa forma, representada pela escrita particular do linguista, e às demais formas da língua, o que implica reconhecer as relações que dão a ela sua condição de existência e seu efeito sobre o linguista, que a segmentou e registrou, a despeito do suporte do sentido. Trata-se de uma clara suspensão da ilusão de que as unidades linguísticas se dão a perceber nelas mesmas. Há uma complexa operação por trás dessa segmentação que articula língua, fala e sujeito/linguista.

Em busca das regularidades, o método de Harris concentra-se, não só na definição das unidades, sua distribuição e ocorrência, para mencionar alguns de seus procedimentos, mas de forma especial na demarcação de limites/fronteiras (segmentation, boundaries e contours) dessas unidades. Esses se mostram móveis e enganadores na sequência verbal e não se apresentam diretamente para o linguista. Junturas, entonações, interrupções, repetições passam a ser consistentemente discutidas pelo método, posto que é preciso cercar a unidade, atribuindo critérios objetivos para que o linguista possa decidir se se trata da mesma unidade, de uma falha na sua realização ou de uma nova unidade.

[...] utterance-end, pauses (including intermittently present pauses), and ends of contour lengths, all occur in the great majority of cases at morphologic boundaries: almost all utterances, intonations, etc. stop not in the middle but at the end of a morpheme (HARRIS, 1960, p. 88) ${ }^{9}$.

Para além da função de "limpeza" do dado em direção às regularidades, o testemunho da "falha" na realização da unidade será apontado como prova da correta definição dos limites, uma vez que se observa ser a falha regida por restrições que operam na língua.

Even interrupted speech hardly ever stops except at the end a phonemelength sound-element (HARRIS, 1960, p. 27) ${ }^{10}$

There are, of course, cases of interrupted utterances which break off in the middle of a morpheme. If we cannot immediately recognize the special status of these utterances, we may include these broken morphemic segments among our elements. Later, we will find that statements true of other morphemes are not true of these, so that the interrupted morphemes will be treated as residues excluded from our

\footnotetext{
8 "Uma forma escrita foneticamente não é, portanto, o registro escrito direto de uma forma falada, mas antes um registro de sua diferença em relação a todas as outras formas faladas da língua".

9 “[...] final de elocuções, pausas (incluindo pausas intermitentes presentes), e extremidades de contornos, todos ocorrem na grande maioria dos casos nas fronteiras morfológicas: quase todas as elocuções, entonações etc. param não no meio mas no fim de um morfema".

10 "Mesmo a fala interrompida quase nunca para, exceto no final da emissão fonética de um fonema".
} 
regular description. In many cases, too, these residues will correlate with special contours (e.g. intonations of hesitation and interruption) (HARRIS, 1960, p. 158 - grifo nosso) ${ }^{11}$.

Não podendo apelar para o sentido (tanto por sua impossibilidade diante de uma língua estrangeira, quanto por exigência do método), mas unicamente para a ocorrência e os limites, a significação restringe-se à semelhança de distribuição das unidades, duramente delimitadas. O reconhecimento da função é tudo o que resta a dizer sobre a significação na língua. Todavia, vale ressaltar que Z. Harris reconhece, com reservas, a possibilidade de que o linguista chegue à demarcação de uma unidade através da apresentação de um enunciado ao informante - um falante nativo, necessariamente - para checar sua aceitação.

Something of this order seems inescapable, at least in the present stage of linguistics: in addition to the data concerning sounds we require data about the hearer's response. However, data about a hearer accepting an utterance or part of an utterance as a repetition of something previously pronounced can be more easily controlled than data about meaning (HARRIS, 1960, p. 20) ${ }^{12}$.

A reserva diante da inevitável necessidade de convocar um informante e observar-lhe a aceitação diante de sua língua sugere o reconhecimento de que, para este falante/ouvinte nada ideal, a língua não pode ser apreendida como pretende fazê-lo o linguista - trata-se, afinal, de sua língua, e isso remete a uma relação que envolve uma escuta singular, inaceitável pelo método. Um falante nativo não é por definição um informante, mas torna-se um "from the point of view of the linguist" (HARRIS, 1960, p. 13) ${ }^{13}$. A relação de um e de outro com a língua não é a mesma. Confiar na reação de um falante nativo diante de um enunciado parece, porém, mais controlável, e por isso preferível ao apelo ao sentido feito pelo linguista, um estrangeiro. Para este último, é preciso restringir-se às cadeias sonoras, onde se esconde o que o linguista procura cernir para além do som, de si mesmo e do falante nativo: a lingua.

\footnotetext{
11 "Há, evidentemente, casos de elocuções interrompidas que param no meio de um morfema. Se não pudermos identificar imediatamente o status desse tipo de elocuções, poderemos incluir esses segmentos morfêmicos partidos entre nossos elementos. Posteriormente, entenderemos que afirmações verdadeiras sobre outros morfemas não o são para esses, de forma que os morfemas interrompidos serão tratados como resíduos excluídos de nossa descrição regular. Em muitos casos, também, esses resíduos estarão associados a contornos especiais (por exemplo, entonação de hesitação e interrupção)".

12 "Coisas dessa ordem parecem inevitáveis, pelo menos, no estado atual da linguística: além dos dados relativos a sons nós precisamos de dados sobre a resposta do ouvinte. De qualquer forma, dados relativos à aceitação do ouvinte de uma elocução ou parte dela como a repetição de alguma coisa previamente pronunciada pode ser mais facilmente controlável do que dados sobre o sentido".

13 "do ponto de vista do linguista".
} 
A respeito desse trabalho, na sua versão de 1951, Benveniste reconhece a precisão quase matemática das condições formais apresentadas pelo autor, para em seguida perguntar:

Consegue-se, ao menos, estabelecer um método único e constante? O autor é o primeiro a convir que são possíveis outros processos, e que alguns seriam mesmo mais econômicos, particularmente quando se faz intervir a significação, de modo que acabamos por perguntar-nos se não há certa gratuidade nesse desdobramento de exigências metodológicas. Observar-se-á sobretudo, porém, que todo o trabalho do linguista se apoia realmente sobre o discurso, implicitamente assimilado à língua (BENVENISTE, 1995, p. 11).

Para Benveniste, trata-se, dentre outras coisas, de delimitar teoricamente os domínios que separam locutor e linguista no que se refere à linguagem, isto é, a língua e o discurso, tema que não ocupa Harris nos termos em que o faz Benveniste ${ }^{14}$. Entretanto, para Z. Harris parece claro que o acesso à língua não é garantido para o falante nativo, nem para o linguista. Não há, portanto, um encontro sensível, nem de um, nem de outro, com unidades linguísticas, o que faz destas construtos de uma teoria e não entidades assimiláveis à fala - não há "identifiable linguistic behavior" ${ }^{15}$-, ou ao conbecimento do falante nativo tolerado como fornecedor de dado, "at least in the present stage of linguistics"

A citação acima convoca outra reflexão de Benveniste em que trata da forma e do sentido na linguagem. Isto é, ao propor o sentido como parte do método para delimitação da forma, o autor traz como exigência que o linguista seja falante da língua, diferentemente do que ocorre na discussão de Harris. Embora muitos dos exemplos criteriosos de Harris sejam extraídos da língua inglesa, a menção ao informante e à definição de seu papel na investigação linguística deixa claro tratar-se do que predominou na linguística americana: o linguista como um estrangeiro/estranho diante da língua de outrem. Essa condição, contudo, não esconde outra conclusão, pode-se dizer que marginal ao método, embora reveladora. Nas páginas de abertura do seu livro-manual, Harris afirma:

These procedures also do not constitute a necessary schedule in the sense that each procedure should be completed before the next is

\footnotetext{
14 Assume-se que a expressão Análise do Discurso foi utilizada pela primeira vez por Z. Harris em um artigo clássico de mesmo nome publicado em 1952. Conforme resume Faraco (2003) “A Análise do/de Discurso não seria para Harris [...] um novo método, mas a expansão do velho método a um novo objeto, objeto que, no fundo, se distingue do velho objeto apenas por sua extensão" (p. 248). Para Benveniste, como dissemos, lingua e discurso referem-se a dominios diferentes.

15 "comportamento linguístico identificável".

16 "ao menos no atual estágio da linguística".
} 
entered upon. In practice, linguists take unnumbered short cuts and intuitive or heuristic guesses, and keep many problems about a particular language before them at the same time: they may have figured out the positional variants of several phonemes before they decide how to cut up into segments certain utterances which presumably contain a phonetically unusual phoneme; and they will usually know exactly where the boundaries of many morphemes are before they finally determine the phonemes. The chief usefulness of the procedures listed below is therefore as a reminder in the course of the original research, and as a form for checking or presenting the results, where it may be desirable to make sure that all the information called for in these procedures has been validly obtained (HARRIS, 1960, p. 1-2 - grifos nossos) ${ }^{17}$.

Ao que parece, o fluxo da fala ("flow of speech") no seu aspecto material, ainda que de uma língua estranha para o linguista, possibilita o reconhecimento de intervalos/segmentos que não se apresentam diretamente dotados de sentido, nos termos de Benveniste, mas como efeito da restrição imposta pela estrutura significante da língua e da afetação do linguista por sua materialidade sonora, diferente do som, já que se trata de um jogo de diferenças, como vimos. Esse reconhecimento parece deslocar Harris em relação ao empirismo que assume guiar a construção do método: este - "a reminder" e "a form for checking" ${ }^{\prime 18}$ - é antes possibilitado pela referida intuição do linguista, e não o contrário.

Ao focar seu trabalho nas vias de entrada do linguista-estrangeiro na língua, definida como "the talk which takes place in a language community" (HARRIS, 1960, p. $13)^{19}$, Harris põe a descoberto de que maneira a forma, nos termos de Benveniste, tem efeito mesmo sobre quem não pode apoiar-se no sentido. Parece-nos, entretanto, que fato semelhante não aconteceria se a fala da comunidade estudada fosse constituída exclusivamente de "sentenças completas" e encadeamentos perfeitos, caso isso fosse possível. As restrições que se revelam justamente em virtude das pausas, das interrupções, enfim, daquilo que falha, permite que o linguista vislumbre regularidades. Aquilo, que no rigor do método aparece como resíduo, revela "special contours" ${ }^{20}$ e transforma-se, assim,

\footnotetext{
17 "Esses procedimentos também não constituem um roteiro obrigatório no sentido de que cada procedimento deveria ser completado antes de o próximo ser introduzido. Na prática, linguistas tomam inúmeros atalhos e suposições intuitivas e heurísticas, e lidam ao mesmo tempo com vários problemas de uma língua particular: eles podem ter compreendido as variantes posicionais de muitos fonemas antes de decidirem como dividir em segmentos certas elocuções que presumivelmente contenham um fonema foneticamente pouco usual; e eles normalmente saberão exatamente onde ficam as fronteiras de muitos morfemas antes mesmo que eles determinem os fonemas. A principal utilidade dos procedimentos listados a seguir é, portanto, ser um lembrete ao longo da pesquisa inicial, e como uma forma de checar ou apresentar os resultados, quando for desejável ter certeza de que toda a informação obtida nesses procedimentos o tenha sido de forma válida".

18 "um lembrete" e "uma forma de verificação".

19 "a fala que ocorre numa comunidade linguística".

20 "contornos especiais".
} 
em possibilidade para a construção de um “objeto homogêneo", ideal da área. Em última instância, a imperfeição sugere que a língua só pode ser pensada como um "todo", como almeja a linguística, porque falha.

\section{De Harris a Chomsky}

Não seria exagero reconhecer nessas passagens de Z. Harris a guinada dada por Chomsky às ideias de seu antigo orientador ${ }^{21}$ - um possível desdobramento do que, em Harris, já assinalava um impasse, talvez uma incoerência em seu empirismo declarado. A intuição do linguista será transformada, primeiramente em competência, e depois, em conbecimento do falante nativo, substituindo-se a prática de constituição de corpus pelo julgamento de aceitabilidade do falante como empiria do modelo ${ }^{22}$ - da fala passa-se assim para a escuta do falante que, ao julgar ser tal ou qual sentença possível em sua língua, atesta o seu conhecimento, isto é, sua Língua- ${ }^{23}$. Interrompem-se os estudos para descrição de línguas "exóticas"; ser falante nativo da língua estudada torna-se condição para fazer linguística ${ }^{24}$. O objeto de análise são as sentenças possiveis, consequentemente perfeitas. $\mathrm{O}$ enunciado (utterance) transforma-se em input para a faculdade da linguagem, adjetivado de imperfeito, por ser logicamente aquém da capacidade geradora do falante, e por ser marcado por falhas, repetições, interrupções, falsos começos; em suma, tudo aquilo que nos pareceu ter guiado a linguística de Harris em direção às regularidades de uma língua que lhe era estranha. Finalmente, opondo-se ao empirismo, a linguística chomskiana, reafirmando seu

\footnotetext{
21 Como assinala Ruwet (1966), a influência de Harris nos primeiros trabalhos de Chomsky pode ser igualmente atestada pelo seu o procedimento 'do morfema ao enunciado', "como fornecendo um modelo generativo da linguagem, destinado, nomeadamente a prever novos factos [...]" (p.12).

22 Referindo-se às críticas lançadas sobre a introdução da noção de gramaticalidade feita pela teoria chomskiana, uma vez que esta apoiava-se na "intuição" do falante, afirma Ruwet (1966): "[...] somos forçados a referir-nos a juízos deste gênero: constituem os dados da linguística: se recusarmos a ter isto em conta, condenamo-nos a 'destruir o próprio objecto da linguística" (p. 49).

${ }^{23}$ Chomsky discutirá, em mais de uma ocasião, as limitações desse julgamento, assumindo que há graus maiores e menores de aceitação e que, em determinados casos, a recusa do falante não poderá ser tomada como garantia. Não vamos nos deter nesse ponto, embora fique registrado que tanto a fala, quanto a escuta de um falante necessariamente testemunham "experiências linguísticas" e, portanto, marcadas pela impossibilidade de garantia de objetividade.

${ }^{24}$ Referindo-se aos estudos de línguas indígenas, tradicionalmente importantes na linguística americana, Chomsky confirma tal postura quando declara: "We began a program under his direction to teach graduate linguistics to Native Americans such as speakers of Navajo or Hopi. We brought them to MIT [...] with the idea that it would be easier to teach them linguistics than for us to learn their languages" (CHOMSKY, 1997, p. 170) ("Iniciamos um programa para ensinar linguística em nível de graduação para Nativos Americanos como os falantes de Navajo ou Hopi. Nós os levamos ao MIT [...] com a ideia de que seria mais fácil ensinálos linguística do que aprendermos suas línguas").
} 
lugar entre as ciências naturais, explicitamente coloca para si o problema lógico da aquisição de linguagem $^{25}$, apelando, nesse momento, para o racionalismo cartesiano e para a psicologia a ele subjacente.

Em oposição a Harris, a imperfeição do input foi tomada por Chomsky como argumento lógico para formular a hipótese da Gramática Universal e conceber a língua como conbecimento. Com isso, inaugura-se na linguística o projeto de estudo da Gramática Gerativa e, indiretamente, demarca-se um espaço de teorização para a área da aquisição de linguagem, qual seja, o intervalo de tempo compreendido entre o estado inicial (a Gramática Universal ou So) e o estado estável (Língua-I ou Ss) do conhecimento do falante ${ }^{26}$.

Esta guinada de um autor a outro é particularmente importante para as considerações sobre a constituição de um falante. A imersão em dados da fala, notadamente da fala do outro, deu a Z. Harris a certeza de não ser possível falar em "identifiable linguistic behavior, much less phonologic or morphologic behavior" 27 , como vimos insistindo. Para Chomsky, um dos pressupostos do modelo de aquisição na perspectiva de Princípios e Parâmetros é o de que as crianças não estão sujeitas a dados negativos. Isto é, os parâmetros necessariamente devem ser visiveis na forma fonética, possibilitando o acesso da criança a eles, independentemente de explícita instrução gramatical sobre o que é ou não aceitável na língua da comunidade. O acesso da criança ao dado primário, responsável pela marcação paramétrica, é entendido como possibilidade de audição: "[...] the differences between languages, then, are small and audible: a child can hear them" (CHOMSKY, 1997, p. 170 - grifos nossos) ${ }^{28}$. A existência de parâmetros na Forma Lógica, onde não ocorre realização fonética, é tida como pouco plausível.

\footnotetext{
${ }^{25}$ Kato (1995) resume a questão colocada pela aquisição de linguagem na teoria gerativa a dois problemas: a) o problema lógico - "o que define a Gramática Universal $(\mathrm{GU})$ e a forma da Língua-I, para que a criança passe quase que instantaneamente do estado inicial (GU) para o terminal (língua-I)?”; b) o problema psicológico "como se dá essa aprendizagem em tempo real?".

${ }^{26}$ No modelo skinneriano, então dominante, sendo a linguagem comportamento operante de tipo verbal e a constituição do repertório comportamental uma constante ao longo da vida do indivíduo, nenhum intervalo de tempo será privilegiado para o tratamento da aquisição da linguagem. A partir de Chomsky, a demarcação de um estado inicial e um estado estável no conhecimento da linguagem revelará que as mudanças ocorridas nesse intervalo de tempo serão qualitativamente diferentes das mudanças surgidas posteriormente. Esse reconhecimento possibilita que uma nova área de investigação se apresente para tratar, em tempo real, dessa passagem idealizada por Chomsky como sendo instantânea. Para uma importante discussão desse período dos estudos em aquisição de linguagem, sugerimos a leitura de LEMOS, M. T. (2002) A língua que me falta, em especial os capítulos 2 e 3 .

27 "comportamento linguístico identificável, muito menos comportamento fonológico ou morfológico".

28 “as diferenças entre as línguas, então, são pequenas e audíveis: uma criança pode ouvi-las".
} 


\section{Z. Harris: a imperfeição e o acesso à lingua}

Núbia Rabelo Bakeker Faria

Se a imperfeição do input é argumento lógico para a GU, supor nele audíveis as diferenças entre as linguas (não se trata de diferenças na lingua, como vimos em Harris) atribui à criança a capacidade de ouvir unidades linguísticas de uma língua particular como meio para adquiri-la, o que levanta questões importantes, sobretudo quando sabemos que "diferenças entre as línguas" neste momento do programa são relacionadas às categorias funcionais. Se a segmentação de unidades linguísticas relacionadas à morfologia, notadamente as de natureza gramatical, se dão a perceber pela audição, qual a necessidade de supor um conhecimento linguístico inato e um input imperfeito?

Entretanto, não podemos ignorar que, no contexto da Gramática Gerativa, falar em criança significa tratá-la do ponto de vista cognitivista assumido por Chomsky. Em um texto de título sugestivo - O que a criança não nos diz: o lugar da empiria no modelo chomskyano -, Lopes (1995) explica: “A partir de 1981, com o modelo de P\&P [Princípios e Parâmetros], a criança chomskiana ganha um novo lugar, aquele da biologia; sua natureza agora é genética" (p. 84 - grifo nosso).

Assim sendo, o input constitui-se em estímulo linguístico bastante especial para essa criança. Nas páginas de abertura de The minimalist program, esclarece o autor: "To attain explanatory adequacy, a theory of language must characterize the initial state of the language faculty and show how it maps experience to the state attained" (CHOMSKY, 1995, p. 3 - grifo nosso $)^{29}$. A natureza genética da criança chomskiana a identifica com a própria faculdade da linguagem, aquela que de fato mapeia a experiência. O input transforma-se agora no que da gramática escapa à audição, ou seja, o seu aspecto estrutural, de assimilação instantânea, só reconhecível pela própria GU - a rigor, falar em audição é apenas força de expressão, trata-se de um mapeamento. Como desdobramento dessa condição, a idealização da instantaneidade da aquisição da linguagem é revista: "A questão empírica séria é quanta distorção é introduzida pela abstração. Um tanto surpreendentemente, talvez, parece que pouca distorção é introdur̨ida, caso alguma o seja: é como se a língua aparecesse instantaneamente" (CHOMSKY, 1998, p. 44 - grifos nossos). A teoria radicaliza ainda o seu descarte da fala e refere-se à possibilidade da telepatia, não fossem as limitações indesejadas do sistema articulatório perceptual que afastam a linguagem de sua perfeição: "If humans could communicate by telepathy, there would be no need for a phonological component, at

\footnotetext{
29 "Para atingir a adequação explanatória, uma teoria de linguagem precisa caracterizar o estado inicial da faculdade da linguagem e mostrar como ele mapeia a experiência para o estado alcançado".
} 
least for the purposes of communication; and the same extends to the use of language generally (CHOMSKY, 1995, p. 221) ${ }^{30}$.

Não nos cabe aqui avançar muito mais na reflexão chomskiana. Interessa-nos destacar que o autor parece empurrar o campo da aquisição de linguagem para um impasse: a teoria que demarca seu espaço de teorização, finda por destituí-la de sua condição de existência. Do descarte da fala em favor do conhecimento do falante, chega-se ao descarte do "tempo", quando a instantaneidade da aquisição deixa de ser idealização teórica para ser concebida como realidade empírica. Ignorar esses desdobramentos da teoria e simplesmente tentar cruzar a barreira entre a perspectiva lógica e a psicológica nesse campo levaria à questionável opção de tomar a audição referida por Chomsky, condição de marcação paramétrica (em última análise, via de aquisição de uma língua particular), equivalente à audição de unidades linguísticas de natureza morfológica diretamente na superfície da fala da comunidade. Nem uma teoria empirista como a de Harris, reconhecidamente a mais rigorosa em seus métodos e procedimentos, cogita essa possibilidade, como vimos.

\section{Conclusão}

Para concluir, diríamos que recuperar a reflexão sobre o método estruturalista, seja aquele sucintamente proposto por Saussure ou aquele exaustivamente elaborado por Z. Harris, expõe impasses e hesitações surgidos em torno da apreensão do próprio da língua, cruciais para enfrentarmos a questão da aquisição. Afinal, não somos telepatas e nossa possibilidade de nos constituirmos sujeitos falantes e de nos comunicarmos não prescinde da fala, da escuta nem do tempo. Além disso, a imperfeição e não a perfeição da linguagem põe à mostra um funcionamento que se dá, tanto na presença de unidades que podem ser vocalizadas, quanto no jogo entre o som e o silêncio, na interrupção, no vazio entre as unidades e no vazio da unidade que não surge, de maneira que a relação e a diferença se instauram. Esses nos parecem lugares necessários e instigantes para pensar a constituição do sujeito falante, assim como a natureza da linguagem bumana.

\footnotetext{
30 "Se os humanos pudessem se comunicar por telepatia, não haveria necessidade de um componente
} fonológico, ao menos com propósitos de comunicação; e o mesmo se estende ao uso da linguagem em geral". 


\section{Referências}

BENVENISTE, Émile. Tendência recentes em linguística geral [1957]. In:

Problemas de Linguística Geral I. Campinas: Pontes, 1995.

BORGES NETO, José. A gramática gerativa transformacional: um ensaio de filosofia da linguagem. Tese (Doutorado em Linguística). Campinas: Universidade Estadual de Campinas, 1991.

CHOMSKY, Noam. Review of B. F. Skinner, "Verbal behavior". Language v. 35, n. 1, 1959, p. 26-58.

The minimalist program. Cambridge; Massachusetts: MIT Press, 1995.

. Chomsky no Brasil. D.E.L.T.A v. 13, Edição Especial, 1997, p. 1-229.

Linguagem e mente: pensamentos atuais sobre antigos problemas.

Brasília: Editora Universidade de Brasília, 1998.

DUCROT, Oswald. Estruturalismo e linguística. São Paulo: Cultrix, 1970.

FARACO, Carlos A. Zellig Harris: 50 anos depois. Revista Letras $n^{\circ}$ 61, especial, 2003, p. 247-252.

HARRIS, Roy. Saussure and his interpreters. 2 ed. Edimburgo: Edinburgh University Press, 2003.

HARRIS, Zellig S. Structural linguistics. Chicago: The University of Chicago Press, 1960.

KATO, M. A. Sintaxe e aquisição na teoria dos princípios e parâmetros. Letras de Hoje v. 30, no 4, Dez. 1995, p. 57-73.

LEMOS, Maria Tereza G. de. A língua que me falta: uma análise dos estudos em aquisição de linguagem. Campinas: Mercado de Letras; São Paulo: Fapesp, 2002.

LOPES, Ruth E. O que a criança não nos diz: o lugar da empiria no modelo chomskyano. Letras de hoje v. 30, nº 4, Dez. 1995, p. 83-89.

RUWET, Nicolas. Introdução. In: ; CHOMSKY, N. A gramática generativa. Lisboa: Edições 70, 1966.

SAPIR, Edward. A linguagem: introdução ao estudo da fala. Rio de Janeiro: Livraria Acadêmica, 1971.

SAUSSURE, Ferdinand de. Curso de linguística geral. São Paulo: Cultrix, 2006.

WHITNEY, William D. A vida da linguagem. Petrópolis: Vozes, 2010. 


\section{Abstract}

This article, of a theoretical nature, reflects on the problems that the division of speech event in segmental elements raise for an innate or a non-innate approach in language acquisition studies, confronting two authors: $Z$. Harris and N. Chomsky. In order to discuss language and the ways of approaching it through speech, Z. Harris in Structural Linguistics pays special attention to definition, distribution and occurrence of linguistic units and also to the definition of its boundaries. The occurrence of failing in the vocal realization of the unit will perform a residual function for the method, but a significant one to attest the correct segmentation: it is noticed that the failing is governed by restrictions that operate in the language. In opposition to Harris' ideas, the input imperfection was taken by Chomsky as a logical argument to the innate bypothesis, inaugurating the Generative Grammar and establishing a theoretical domain for the language acquisition area. What was qualified as imperfect by Chomsky appears in Harris' linguistics as a way to access the data and entering someone's language.

Keywords: Speech. Segmentation. Language units. Imperfection. Input 